\title{
In Shemoriam
}

Dr. Mauricio Gonzaga de Castro

1945-2013

Mauricio Gonzaga de Castro, nasceu na cidade de Goiás Velho em primeiro de dezembro de 1945. Cursou a Faculdade Nacional de Medicina, atualmente UFRJ, ainda na Praia VermeIha, formando-se em 1971. Fez Residência em Ortopedia e Traumatologia no Serviço do Prof. Nova Monteiro no Hospital Miguel Couto em 1972 e 1973. Após o término, chegou a voltar para sua terra natal, porém logo retornou ao Rio de Janeiro para trabalhar. Inicialmente atuou no INTO e, em seguida, iniciou sua carreira docente, ingressando como Professor Auxiliar na Faculdade de Ciências Médicas (FCM) da UERJ. Atualmente era Professor Associado. Além disso, era Mestre e Livre Docente em Ortopedia. Foi Chefe de Clínicas, Chefe da Unidade Docente Assistencial de Ortopedia e Chefe do Departamento de Cirurgia Especializa da FCM-UERJ. Chegou a Diretor do Hospital Universitário Pedro Ernesto na década de 90. Foi Presidente da SBOT-RJ no biênio 1986-1987. Nesta época havia uma cisão na Ortopedia do Rio de Janeiro. Havia o grupo do Prof. Nova e o grupo do prof. Dagmar Chaves. Mauricio, sendo docente de um dos serviços e ex-residente do outro, participou ativamente do processo de pacificação, unindo os grupos e possibilitando um grande avanço na Ortopedia fluminense. Nesta época, a Regional teve sua primeira sede, na rua Visconde Pirajá, em Ipanema. No âmbito nacional, Mauricio foi membro da Comissão de Ensino e Treinamento (CET) e da comissão organizadora de vários congressos brasileiros de Ortopedia. Foi, também, durante cinco anos, Coordenador da Câmara Técnica de Ortopedia do CREMERJ. Dedicou-se à cirurgia da coluna vertebral tendo sido consultor da Revista Brasileira de Coluna e membro do Corpo Editorial da Revista Brasileira de Ortopedia. Era casado com Ângela, companheira desde os primeiros passos na Medicina. Deixa duas filhas, três netos e muitos amigos.

Dr. Renato Graça 